\title{
The effect of the yeast, Saccharomyces cerevisiae, on the fibrolytic activity in the rumen and on nutrient digestibility in the digestive tract of cows
}

\author{
B. Kowalik', J.J. Pająk, Z. Długołęcka, J. Rawa and T. Michałowski \\ The Kielanowski Institute of Animal Physiology and Nutrition, \\ Polish Academy of Sciences \\ 05-110 Jabłonna, Poland
}

\begin{abstract}
The influence of live Saccharomyces cerevisiae yeast on the fibrolytic activity in rumen digesta and on total digestive tract nutrient digestibility in cows was examined in a $2 \times 2$ Latin square design. The animals were fed hay-concentrate diet alone or supplemented with yeast at the rate of $5 \mathrm{~g} / \mathrm{d}$. Addition of Sacchromyses cerevisiae decreased the activity of CMC-ase and xylanase when measured before feeding but had no effect on the diurnal variations in activity of these enzymes. The digestibility of dry matter, organic matter, crude fibre, ADF and NDF was not affected.
\end{abstract}

KEY WORDS: ruminants, yeast, carboxymethylocellulase, xylanase, fibre digestibility

\section{INTRODUCTION}

Interest in the use of live yeast, particularly Saccharomyces cerevisiae, as a feed additive for ruminants has increased in recent years. Yeasts increase the number of cellulolytic bacteria as well as NDF and ADF digestion in the rumen (Newbold et al., 1995; Putman et al., 1997). The increase in bacterial number probably results from improvement in the anaerobic status of rumen digesta (Newbold et al., 1996). The mechanism by which yeast cultures act on the microbial population still remains unknown, however. The objective of this study was to investigate the effect of live Saccharomyces cerevisiae yeast on the activity of carboxymethylcellulase (CMC-ase) and xylanase in rumen digesta as well as on total digestive tract nutrient digestibility in cows.

\footnotetext{
${ }^{1}$ Corresponding author: e-mail: b.kowalik@ifzz.pan.pl
} 


\section{MATERIAL AND METHODS}

The experiment was carried out on two rumen-fistulated Black-and-White Lowland cows in a Latin $2 \times 2$ square design. The animals were fed $8 \mathrm{~kg}$ of a diet containing, \%: meadow hay 87, and concentrate 13 (crushed barley, rapeseed oilmeal, soyabean oilmeal). A dose of $5 \mathrm{~g} / \mathrm{d}$ live cultures of Saccharomyces cerevisiae $\left(1 \cdot 10^{10} \mathrm{CFU} / \mathrm{g}\right)$ was introduced via the fistula directly into the rumen of the experimental animals. The daily ration was given at 8.00 and $16.00 \mathrm{~h}$ in two equal portions, whereas the yeast was given once a day. Water was offered ad libitum. The preliminary feeding period lasted 4 weeks and was followed by the sampling of rumen digesta. The samples were collected just before and 2, 4 and $8 \mathrm{~h}$ after the morning feeding. Mordant $\left(\mathrm{K}_{2} \mathrm{Cr}_{2} \mathrm{O}_{7}\right)$ at the rate of $40 \mathrm{~g} / \mathrm{d}$ was given during the last 7 days of the experiment as a marker of indigestible matter. Faeces were collected during the last 5 days. Enzymes were extracted from the rumen contents using $\mathrm{CCl}_{4}$ according to Huhtanen and Khalili (1992) and used to determine the activities of CMC-ase and xylanase according to Miller et al. (1960). The analyses of feed and faeces dry and organic matter, crude fibre, ADF, NDF, and $\mathrm{Cr}$ were performed using standard methods (AOAC, 1990). The digestibility of particular nutrients was calculated on the basis of the proportion of chromium and acid-insoluble ash (AIA) in feed and in faeces. AIA was determined according to Van Keulen and Yang (1977).

\section{RESULTS AND DISCUSSION}

The effect of yeast on the total digestibility of nutrients depended on the marker used (Table 1). The obtained results are thus in agreement with the findings of Miller-Webster et al. (2002).

Table 1. Effect of Saccharomyces cerevisiae on the total digestive tract digestibility of nutrients, $\%$. Mean values $(\mathrm{n}=6)$

\begin{tabular}{lccccccc}
\hline \multirow{2}{*}{ Nutrient } & \multicolumn{3}{c}{$\mathrm{K}_{2} \mathrm{Cr}_{2} \mathrm{O}_{7}$} & & \multicolumn{3}{c}{ AIA } \\
\cline { 2 - 4 } \cline { 7 - 8 } Dry matter & control & yeast & SEM & & control & yeast & SEM \\
Organic matter & 73.37 & 73.69 & 2.254 & & 70.82 & 76.97 & 2.908 \\
Crude fibre & 74.21 & 77.74 & 1.930 & & 74.43 & 80.39 & 2.830 \\
ADF & 70.42 & 71.40 & 2.628 & & 67.04 & 75.15 & 3.892 \\
NDF & 78.86 & 79.38 & 1.614 & & 76.33 & 81.71 & 2.567 \\
\hline
\end{tabular}

SEM - standard error of mean 
No differences were found between the total digestive tract digestibility of feed in control and experimental animals. This suggests that live cultures of Saccharomyces cerevisiae had no effect on the digestion processes in the rumen or that their influence was masked by greater hindgut fermentation in control - as compared with the experimental animals (Williams, 1989; Williams and Newbold, 1990). Due to this, total tract digestibility studies do not characterize the effect of the added yeast on the digestive processes in the rumen.

Introducing Sacccharomyces cerevisiae into the rumen resulted in a decrease in carboxymethylcellulase (CMC-ase) and xylanase activity in ruminal digesta just before feeding (Table 2). This finding suggests a negative effect of Saccharomyces cerevisiae on the activity and/or number of fibrolytic species of ruminal microorganisms, but not on the digestibility of fibrous nutrients (Michałowski et al., 2003).

Table 2. Effect of yeast on fibrolytic enzyme activities in the rumen content of cows, $\mu \mathrm{M}$ released reducing sugars/gDM/min

\begin{tabular}{cccccccc}
\hline \multirow{2}{*}{$\begin{array}{l}\text { Hours after } \\
\text { feeding }\end{array}$} & \multicolumn{3}{c}{ CMC-ase } & & \multicolumn{3}{c}{ Xylanase } \\
\cline { 2 - 4 } \cline { 6 - 8 } \cline { 6 - 8 } & control & yeast & SEM & & control & yeast & SEM \\
\hline 0 & 12.48 & $9.95^{* *}$ & 0.612 & & 162.63 & $138.79^{* *}$ & 7.806 \\
2 & 6.22 & 5.13 & 0.653 & & 109.53 & 104.29 & 6.088 \\
4 & 6.18 & 5.04 & 0.456 & & 110.94 & 100.31 & 5.744 \\
8 & 7.94 & 7.49 & 0.539 & & 127.22 & 122.44 & 5.515 \\
\hline
\end{tabular}

** $-\mathrm{P} \leq 0.01$

It was found that the activity of CMC-ase and xylanase decreased after feeding and then increased and that the yeast did not affect the pattern of these changes. The observed decrease was perhaps a dilution effect of the newly ingested feed, while the increase, of the progressing colonization of feed particles by fibrolytic microorganisms.

\section{CONCLUSIONS}

No relationship was found between the supplementation of feed with live cultures of Saccharomyces cerevisiae and the total digestive tract digestibility of nutrients in cows. Nonetheless, the yeast supplement did lower the activity of the ruminal CMCase and xylanase. The latter finding argues in favour of changes in rumen microbial populations rather than a decline in the digestibility of fibrous components of the diet. Further studies on the changes in the numbers of cellulolytic bacteria, fungi and protozoa are needed, therefore, to explain the obtained results. 


\section{REFERENCES}

AOAC, 1990. Official Methods of Analysis, Association of Official Analytical Chemists. $15^{\text {th }}$ Edition. Arlington, VA

Huhtanen P.P., Khalili H., 1992. The effect of sucrose supplement on the particle-associated carboxymethylcellulase (EC 3.2.1.4) and xylanase (EC 3.2.1.8) activities in cattle given grasssilage-based diet. Brit. J. Nutr. 67, 245-255

Michałowski T., Bełżecki G., Kwiatkowska E., Pająk J.J., 2003. The effect of selected rumen fauna on fibrolytic enzyme activities, bacterial mass, fibre disappearance and fermentation pattern in sheep. J. Anim. Feed Sci. 12, 45-64

Miller G.L., Blum R., Glennon W.E., Butron A.L., 1960. Measurement of carboxymethylcellulase activity. Anal. Biochem. 2, 127-132

Miller-Webster T., Hoover W.H., Holt M., Nocek J.E., 2002. Influence of yeast culture on ruminal microbial metabolism in continuous culture. J. Dairy Sci. 85, 2009-2014

Newbold C.J., Wallace R.J., Chen X.B., McIntosh F.M., 1995. Different strains of Saccharomyces cerevisiae differ in their effects on ruminal bacterial numbers in vitro and in sheep. J. Anim. Sci. 73, 1811-1818

Newbold C.J., Wallace R.J., Chen X.B., McIntosh F.M., 1996. Mode of action of the yeast Saccharomyces cerevisiae as a feed additive for ruminants. Brit. J. Nutr. 76, 249-261

Putman D.E., Schwab C.G., Socha M.T., Whitehouse N.L., Kierstead N.A., Garthwaite B.D., 1997. Effect of yeast culture in the diets of early lactation dairy cows on ruminal fermentation and passage of nitrogen fractions and amino acids the small intestine. J. Dairy Sci. 80, 374-384

Van Keulen J., Yang B.A., 1977. Evaluation of acid-insoluble ash a natural marker in ruminant digestibility studies. J. Anim. Sci. 44, 282-287

Williams P.E.V., 1989. The mode of action of yeast culture in ruminal diets: a review of the effect on rumen fermentation patterns. Biotechnology in the feed industry. Alltech Tech. Publ., Nicholasville, KY, pp. 65

Williams P.E.V., Newbold C.J., 1990. Rumen probiosis: the effect of novel microorganism on rumen fermentation and ruminant productivity. In: W. Haresign, D.J.A. Cole (Editors). Recent Advances in Animal Nutrition. Butterworths, London, pp. 211-227 